\title{
Abstract The Effect of Thick Blanket Distribution and Room Temperature Adjustment toward Body Temperature Change of Post Surgery Patients in the Recovery Room of Central Surgical Installation of Type B Hospital Gorontalo Province
}

\author{
Pipin Yunus \\ University Of Muhammadiyah Jakarta Indonesia \\ ns.piyu@gmail.com
}

\begin{abstract}
Surgery is a kind of invasive treatment by performing an incision on human body which is ended with surgical wounds closure and suturing. The main objective of this research is to find out the effectiveness of thick blanket distribution and room temperature adjustment. The design of this research is Quasi Experimental research with pre-post test control group design. The researcher used accidental sampling with 45 research samples. The result of this research is obtained through the use of Paired T-Test. The result of statistical test showed the differences of thick cotton blanket group in body temperature $36.486^{\circ} \mathrm{C}$ with standard deviation value $0.324^{\circ} \mathrm{C}$ and room temperature adjustment after intervention toward the changes of patient's body temperature $36.833^{\circ} \mathrm{C}$ with standard deviation value $0.205^{\circ} \mathrm{C}$. There are significant differences in the changes of patient's body temperature after intervention between thick cotton blanket group and room temperature adjustment $22^{\circ} \mathrm{C}$ with Significant P-Value $0.002 \leq \alpha 0.05$. Suggestion: the thick blanket distribution to post surgery patients and room temperature adjustment are recommended to be carried out by the nurse to increase the body temperature of the patients and it can be applied in Nursing Care to post surgery patients in the recovery room.
\end{abstract}

Keywords: Thick Blanket, Room Temperature Adjustment, Post Surgery. 


\section{PENDAHULUAN}

Selama beberapa tahun terakhi masyarakat Indonesia mengalami perkembangan dan peningkatan angka kesakitan dan kematian. Untuk mengatasi berbagai macam keluhan penyakit berbagai tindakan telah dilakukan, mulai dari tindakan paling ringan yaitu secara konservatif atau non bedah sampai pada tindakan yang paling berat yaitu operatif atau tindakan bedah.Data WHO tahun 2016 menunjukkan bahwa selama lebih dari satu abad, perawatan bedah menjadi komponen penting dari perawatan kesehatan diseluruh dunia. Diperkirakan setiap tahun 230 juta tindakan bedah dilakukan diseluruh dunia. Data tabulasi nasional departemen kesehatan Republik Indonesia tahun 2009, menjabarkan bahwa tindakan bedah menempati urutan ke sebelas dari lima puluh pola penyakit di Indonesia.

Indonesia sendiri insiden tindakan operasi yang paling banyak terjadi di tahun 2015 mencapai 591,819 orang dan meningkat pada tahun 2016 sebesar 596,132 orang.Berdasarkan data yang di dapatkan pada Balai Kesehatan Provinsi Gorontalo (Dikes Provinsi Gorontalo) jumlah pasien dengan tindakan operasi secara keseluruhan mencapai sebanyak 891 orang di tahun 2014 dan 986 orang di tahun 2015 telah mengalami peningkatan sebanyak 992pada tahun 2016 dan rata-rata pasien yang mengalami kedinginan setelah post operasi 384 orang di tahun 2015, 392 orang di tahun 2016. Berdasarkan data dari medical record di Rumah Sakit Tipe B Provinsi Gorontalo jumlah pasien post operasi dengan menggunakan anastesi umum atau general sebanyak 780 orang pada tahun 2014, pada tahun 2015 sebanyak 786 pasien dan pada tahun 2016 sebanyak 793 pasien.

Berdasarkan studi pendahuluan jumlah pasien post operasi terus meningkat sehingga akan berdampak terhadap peningkatan perubahan suhu tubuh dengan reaksi menggigil diakibatkan oleh faktor lingkungan dan obat anastesi yang diberikan. Dengan adanya peningkatan perubahan suhu ini beberapa upaya yang sudah dilakukan adalah dengan memberikan selimut dan menaikan suhu ruangan untuk mengstabilkan suhu tubuh pasien. Namun dari hasil observasi dan wawancara kepala ruangan yang didapatkan dilapangan tindakan mandiri sangat kurang dilakukan oleh perawat mengingat jumlah tenaga yang kurang dan tindakan operasi yang banyak sehingga perawat tidak melakukan intervensi keperawatan terhadap pasien dan mengakibatkan banyak pasien yang mengalami penurunan suhu tubuh.

\section{Method}

Penelitian akan dilakasanakan di Ruang Pemulihan Instalasi bedah Sentral Rumah Sakit Tipe B Provinsi Gorontalo. Jenis penelitian ini adalah Quasi Experiment dengan rancangan pre-post test Control Group Desain. Desain penelitian ini digunakan untuk mengetahui perbandingan antara perubahan suhu tubuh pada kelompok yang mendapatkan intervensi selimut tebal dan kelompok yang dapat pengaturan suhu ruangan serta kelompok kontrol yang tidak mendapatkan intervensi, Pengambilan sampel disini dilakukan dengan teknik Accidental sampling.Accidental 
sampling yaitu teknik penentuan sampel berdasarkan kebetulan,siapa saja yang secara kebetulan bertemu dengan peneliti yang sesuai dengan kriteria penelitian (Sugiono, 2013).Waktu penelitian dilaksanakan pada bulan Desember 2016 sampai Januari 2017. Uji statistic yang dilakukan peneliti adalah dengan menggunakan Paired t test.

Langkah capaian peneliti bekerjasama dengan kepala ruangan atau perawat di ruang pemulihan untuk membantu pelaksanaan penelitian.Adapun perawat yang membantu penelitian memiliki kriteria pandidikan minimal D3 keperawatan. Peneliti melakukan pengontrolan responden sesuai kriteria inklusi. Peneliti menentukan responden pasien post operasi di rung pemulihan Instalasi Bedah Sentral. Pelaksanaan penelitian dilakukan anatar kelompok intervensi dan kelompok control. Peneliti memperkenalkan diri kepada calon responden, menjelaskan tujuan penelitian dan prosedur penelitian, dan meminta kesediaan calon responden untuk berpartisipasi sebagai responden dalam penelitian. Peneliti dan responden dari ketiga kelompok membuat kontrak untuk pelaksanaan pre-test, intervensi dan post-test. Pre test. mengukur suhu tubuh dengan menggunakan thermometer air raksapada axila pasien post operasi jam pertama setelah berada di ruang pemulihan selama 10 menit dengan suhu ruangan $16^{\circ} \mathrm{C}$. Pemberian intervensi kepada 3 kelompok masing-masing kelompok intervensi I dengan selimut tebal kain katun sesuai dengan suhu ruangan $16^{\circ} \mathrm{C}$ di ruang pemulihan rumah sakit sebanyak 15 orang, kelompok intervensi II pengaturan suhu ruangan sesuai dengan standar $16^{\circ} \mathrm{C}$ menjadi $22^{\circ} \mathrm{C}$ dengan selimut dari keluarga sebanyak 15 orang dan kelompok Kontrol yang menggunakan selimut keluarga dan pengaturan suhu ruangan $16^{\circ} \mathrm{C}$ sesuai dengan suhu ruang pemulihan sebanyak 15 orang. Intervensi yang diberikan selama 60 menit sesuai SOP masing masing. Pada Post test: mengukur suhu tubuh dengan menggunakan thermometer air raksa selama 10 menit setelah diberikan intervensi selimut tebal jenis kain katun, mengatur suhu ruangan $16^{\circ} \mathrm{C}$ menjadi $22^{\circ} \mathrm{C}$ dan kelompok kontrol untuk mengetahui perbedaan suhu tubuh sebelumnya dan setelah diberikan intervensi dengan suhu ruangan $16^{\circ} \mathrm{C}$.

\section{Result and Discussion}

Tabel 3.1 Distribusi Responden

menurut Karakteristik Variabel

\begin{tabular}{|c|c|c|c|c|c|c|}
\hline & \multicolumn{2}{|c|}{$\begin{array}{c}\text { Interven } \\
\text { si I }\end{array}$} & \multicolumn{2}{|c|}{$\begin{array}{c}\text { Interven } \\
\text { si II }\end{array}$} & \multicolumn{2}{|c|}{ Kontrol } \\
\hline & $f$ & $\%$ & $f$ & $\%$ & $F$ & $\%$ \\
\hline \multicolumn{7}{|l|}{ Usia } \\
\hline 25 - 35 tahun & 4 & 26.7 & 3 & 20.0 & 7 & 46.7 \\
\hline $36-45$ tahun & 6 & 40.0 & 12 & 80.0 & 8 & 53.3 \\
\hline 46 - 55 tahun & 5 & 33.3 & - & - & - & \\
\hline \multicolumn{7}{|l|}{ Jenis } \\
\hline Kelamin & 8 & 53.3 & 6 & 40.0 & 6 & 40.0 \\
\hline Laki-laki & 7 & 46.7 & 9 & 60.0 & 9 & 60.0 \\
\hline \multicolumn{7}{|l|}{ Perempuan } \\
\hline \multicolumn{7}{|l|}{ Pendidikan } \\
\hline SD & 6 & 40.0 & 1 & 6.7 & 3 & 20.0 \\
\hline SMP & 5 & 33.3 & 6 & 40.0 & 5 & 33.3 \\
\hline SMA & 4 & 26.7 & 8 & 53.3 & 7 & 46.7 \\
\hline \multicolumn{7}{|l|}{ Diagnosa } \\
\hline Laparatomi & 6 & 40.0 & 3 & 20.0 & 4 & 26.7 \\
\hline Struma & 5 & 33.3 & 3 & 20.0 & 2 & 13.3 \\
\hline Tumor & 4 & 26.7 & 3 & 20.0 & 4 & 26.7 \\
\hline THT & - & - & 6 & 40.0 & - & - \\
\hline Ca Mamae & - & - & - & - & 5 & 33.3 \\
\hline
\end{tabular}

Sumber : Data Primer (2016) 
Tabel 3.1 menunjukan pada kelompok intervensi pemberian selimut tebal kain katun sebagian besar responden berusia $36-45$ tahun (40\%), pada kelompok intervensi pengaturan suhu ruangan berusia $36-45$ tahun (80\%) dan pada kelompok kontrol berusia $25-35$ tahun $(46.7 \%)$, pada kelompok intervensi pemberian selimut tebal kain katun sebagian besar responden jenis kelamin laki laki (53.3\%), pada kelompok intervensi pengaturan suhu ruangan jenis kelamin perempuan (60\%) dan pada kelompok kontrol jenis kelamin perempuan (60\%), pada kelompok intervensi pemberian selimut tebal kain katun sebagian besar responden berpendidikan SD (40\%), pada kelompok intervensi pengaturan suhu ruangan berpendidikan SMA (53.3\%) dan pada kelompok kontrol berpendidikan SMA (46.7\%). Pada kelempok intervensi pemberian selimut tebal kain katun sebagian besar responden diagnosa medis Laparatomi (40.0\%), pada kelompok intervensi pengaturan suhu ruangan diagnosa medis THT $(40.0 \%)$, dan pada kelompok kontrol diagnosa medis Ca Mamae (33.3\%).

Table 3.2 Suhu tubuh sebelum dan setelah intervensi di Ruang

Pemulihan Instalasi Bedah Sentral Rumah Sakit Tipe B Provinsi Gorontalo 2016

\begin{tabular}{lllll}
\hline \multicolumn{1}{c}{ Variabel } & Mean & SD & SE & N \\
& & & & \\
Intervensi I & & & & \\
Pre intervensi & 35.20 & 0.57 & 0.14 & 15 \\
Post intervensi & 36.48 & 0.32 & 0.83 & \\
Intervensi II & & & & \\
Pre intervensi & 35.46 & 0.46 & 0.11 & 15 \\
Post intervensi & 36.83 & 0.20 & 0.05 & \\
Kontrol & & & & \\
Pre intervensi & 35.12 & 0.77 & 0.02 & 15 \\
\hline
\end{tabular}

\begin{tabular}{c}
\hline Post intervensi $35.14 \quad 0.82 \quad 0.02$ \\
\hline Sumber: Data Primer (2016) \\
Table 3.2 menunjukan dari 15
\end{tabular} responden dengan menggunakan uji-t bahwa nilai rata-rata perubahan suhu tubuh sebelum dilakukan intervensi pemberian selimut tebal kain katun dengan suhu ruangan $16^{\circ} \mathrm{C}$ adalah 35.20 dan rata rata perubahan suhu tubuh setelah dilakukan intervensi pemberian selimut tebal kain katun silk adalah 36.48.artinya ada perubahan suhu tubuh,pada kelompok intervensi II menunjukan dari 15 responden dengan menggunakan uji-t bahwa nilai ratarata perubahan suhu tubuh sebelum dilakukan intervensi pengaturan suhu ruangan $16^{\circ} \mathrm{C}$ adalah 35.46 dan rata rata perubahan suhu tubuh setelah dilakukan intervensi pengaturan suhu ruangan $22^{\circ} \mathrm{C}$ adalah 36.83 artinya ada perubahan suhu tubuh dan pada kelompok control dari 15 responden dengan menggunakan uji-t nilai ratarata perubahan suhu tubuh sebelum dilakukan intervensi pada kelompok kontrol dengan suhu ruangan $16^{\circ} \mathrm{C}$ adalah 35.12 dan nilai rata rata setelah 60 menit adalah 35.14 artinya tidak ada perubahan dalam peningkatan suhu tubuh.

Tabel 3.3 Hasil Analisa Bivariat Perbedaan pemberian selimut tebal jenis kain katun, pengaturan suhu ruangan $22^{\circ} \mathrm{C}$ dan kelompok kontrol di Ruang Pemulihan Instalasi Bedah Sentral Rumah Sakit Tipe B Provinsi Gorontalo.

\begin{tabular}{|c|c|c|c|c|}
\hline Variabel & Mean & SD & \begin{tabular}{|c|}
$\mathrm{P}-$ \\
value
\end{tabular} & $N$ \\
\hline \multicolumn{5}{|c|}{ ntervensi I } \\
\hline $\begin{array}{c}\text { Pre dan } \\
\text { post }\end{array}$ & -1.280 & 0.426 & 0.000 & 15 \\
\hline \multicolumn{5}{|l|}{ Intervensi } \\
\hline II & -1.366 & 0.483 & 0.000 & 15 \\
\hline
\end{tabular}


Pre dan

post

Kontrol

$\begin{array}{lllll}\text { Pre dan } & -0.020 & 0.041 & 0.082 & 15\end{array}$

post

Sumber : Data primer (2016)

Tabel 5.3 menunjukan rata-rata perbedaan perubahan suhu tubuh antara sebelum dan sesudah pada kelompok intervensi I adalah- $1.280^{\circ} \mathrm{C}$ dengan standar deviasi $0.426^{\circ} \mathrm{C}$. analisis uji t berpasangan menunjukan ada perbedaan rata-rata perubahan suhu tubuh yang signifikan dengan nilai $p=0.00$. rata rata-rata perbedaan perubahan suhu tubuh antara sebelum dan sesudah pada kelompok intervensi II adalah- $1.366^{\circ} \mathrm{C}$ dengan standar deviasi $0.483^{\circ} \mathrm{C}$ analisis uji t berpasangan menunjukan ada perbedaan rata-rata perubahan suhu tubuh yang signifikan dengan nilai $p=0.00$ dan rata-rata perbedaan perubahan suhu tubuh antara sebelum dan sesudah pada kelompok kontrol adalah- $0.020^{\circ} \mathrm{C}$ dengan standar deviasi $0.041^{\circ} \mathrm{C}$. analisis uji $t$ tidak berpasangan menunjukan tidak ada perbedaan rata-rata perubahan suhu tubuh yang signifikan dengan nilai $p=0.082$.

Table 3.4 Efektifitas pemberian selimut tebal kain katun dan pengaturan suhu ruangan terhadap perubahan suhu tubuh di Ruang Pemulihan Instalasi Bedah Sentral Rumah Sakit Tipe B Provinsi Gorontalo

\begin{tabular}{l|c|c|c|c|c}
\hline Variable & Mean & SD & SE & $\begin{array}{c}p- \\
\text { value }\end{array}$ & $N$ \\
\hline Posttest & & & & & 15 \\
Selimut tebal & 36.486 & 0.324 & 0.083 & & 15 \\
$\begin{array}{l}\text { Pengaturan } \\
\text { Suhu }\end{array}$ & 36.833 & 0.205 & 0.053 & & \\
Ruangan & & & 0.002 & \\
\hline
\end{tabular}

Sumber : Data primer (2016)
Tabel 5.4 menunjukan rata-rata pada kelompok selimut tebal kain katun setelah diberikan intervensi terhadap perbedaan suhu tubuh $36.486^{\circ} \mathrm{C}$ dengan standar deviasi $0.324^{\circ} \mathrm{C}$ dan rata-rata pada kelompok pengaturan suhu ruangan setelah diberikan intervensi terhadap perubahan suhu tubuh $36.833^{\circ} \mathrm{C}$ dengan standar deviasi $0.205^{\circ} \mathrm{C}$. terdapat perbedaan yang bermakna dalam perubahan suhu tubuh setelah intervensi antara kelompok selimut tebal kain katun dan pengaturan suhu ruangan $22^{\circ} \mathrm{C}$ dengan nilai signifikan p-value $0.002 \leq \alpha 0.05$.

Interpretasi hasil penelitian dijelaskan sesuai dengan tujuan penelitian yaitu mengetahui efektifitas pemberian selimut tebal dan pengaturan suhu ruangan terhadap perubahan suhu tubuh pasien post operasi di Ruang Pemulihan Instalasi Bedah Sentral Rumah Sakit Tipe B Provinsi Gorontalo

1. Karakteristik responden

Responden dalam penelitian ini berjumlah 45 orang yang mengalami perubahan suhu tubuh.

a. Usia

Responden penelitian yang menjalani post opeasi pada pada kelompok intervensi I sebagian besar responden berusia $36-45$ tahun (40\%), pada kelompok intervensi II berusia 36-45 tahun (80\%) dan pada kelompok kontrol berusia 25 - 35 tahun (46.7\%),Pada hasil penelitian yang didapatkan lebih banyak kategori usia 36 - 46 tahun yang melakukan operasi dengan menggunakan anastesi umum. Pada usia responden lebih tua akan mempunyai resiko terhadap perubahan suhu tubuh yang 
diakibatkan faktor fisiologis dan daya tahan tubuh yang menurun.

Usia penelitian ini hamper sama dengan penelitian yang dilaksanakan oleh harun (2015). Dalam penelitian tersebut dilibatkan responden dari usia 25 sampai 55 tahun.

Penelitian ini sejalan dengan teori Black (2014) yang menyatakan pada usia lanjut mempunyai resiko lebih besar dikarenakan cadangan fisiologis pada usia tua sudah sangat menurun atau tingkat metabolisme tubuh secara umum melambat sehingga hilangnya jaringan otot diakibatkan perubahan hormonal dan neurologis (saraf).

b. Jenis Kelamin

Responden penelitian post operasi pada kelompok intervensi I sebagian besar responden jenis kelamin laki laki (53.3\%), pada kelompok intervensi II jenis kelamin perempuan $(60 \%)$ dan pada kelompok kontrol jenis kelamin perempuan (60\%).

Hasil penelitian menunjukan jumlah responden yang paling banyak adalah perempuan hal ini dikarenakan perempuan lebih berisiko terjadi perubahan suhu tubuh yang diakbiatkan aktivitas yang dimiliki oleh perempuan lebih sedikit dibandingkan dengan laki-laki. Penelitian ini sesuai dengan teoriAnas (2007) menyatakan jenis kelamin sangat mempengaruhi kegiatan metabolisme, suhu tubuh pria lebih tinggi daripada wanita. Suhu tubuh wanita dipengaruhi daur haid pada saat ovulasi dan suhu tubuh wanita pada pagi hari saat bangun meningkat $0,3-0,5^{\circ} \mathrm{C}$.

c. Pendidikan

Pendidikan pasien post operasi pada kelompok intervensi I sebagian besar responden berpendidikan SD
(40\%), pada kelompok intervensi II berpendidikan SMA (53.3\%) dan pada kelompok kontrol berpendidikan SMA $(46.7 \%)$. Hasil penelitian yang didapatkan paling banyak adalah pendidikan SMA. Tingkat pendidikan merupakan indikator seseorang telah menempuh jenjang pendidikan formal dan umumnya berpengaruh terhadap kemampuan dalam mengola informasi yang diperoleh pada pasien pada saat sebelum dan sesudah intervensi

d. Diagnose medis

Diagnose medis pasien post operasi Pada kelempok intervensi I sebagian besar responden diagnosa medis Laparatomi (40.0\%), pada kelompok intervensi II diagnosa medis THT (40.0\%), dan pada kelompok kontrol diagnosa medis $\mathrm{Ca}$ Mamae (33.3\%). Hasil penelitian yang didaptkan paling banyak diagnosa medis laparatomi dan THT.Diagnosa medis merupakan salah satu indicator untuk dilakukan operasi yang menggunakan anastesi generalatau umum.

Jenis operasi besar yang membuka rongga tubuh, misal pada operasi rongga toraks atau abdomen, akan sangat berpengaruh terhadap angka kejadian hipotermia. Operasi abdomen dikenal sebagai penyebab hipotermia karena berhubungan dengan operasi yang berlangsung lama, insisi yang luas, dan sering membutuhkan cairan guna membersihkan ruang peritoneum. Keadaan ini mengakibatkan kehilangan panas yang terjadi ketika permukaan tubuh pasien yang basah serta lembab, seperti perut yang terbuka dan juga luasnya paparan permukaan kulit. Evaporasi adalah proses perubahan sifat fisika dari bentuk zat cair ke dalam bentuk gas, 
disertai pelepasan sejumlah panas sebanyak $20-27 \%$.

2. Perbedaan suhu tubuh sebelum dan setelah pemberian selimut tebal jenis kain katun

Terdapat perbedaan perubahan suhu tubuh sebelum dan setelah intervensi pemberian selimut tebal kain katun dengan suhu $16^{\circ} \mathrm{C}$ pada pasien post operasi didapatkan sebelum diberikan intervensi rata-rata $35.20^{\circ} \mathrm{C}$ dan setelah diberikan intervensi terjadi peningkatan suhu tubuh dengan nilai rata rata $36.48^{\circ} \mathrm{C}$ dengan selisi nilai rata rata sebesar $1,28^{\circ} \mathrm{C}$ hal ini menunjukan ada perbedaan yang bermakna perubahan suhu tubuh sebelum dilakukan intervensi dan setelah dilakukan intervensi pada pasien pasca operasi.

Pemberian selimut tebal jenis kain katun dapat mempengaruhi terhadap perubahan suhu tubuh pasien hal ini karenakan pada selimut tebal dapat menjaga radiasi agar tidak keluar dari tubuh sehingga pasien merasa lebih nyaman.

Lingkungan ruang operasi dan ruang pemulihan sangat dingin.Penurunan tingkat fungsi tubuh klien menyebabkan turunnya metabolisme dan menurunkan suhu tubuh. Apabila klien mulai sadar, mereka mungkin akan mengeluh kedinginan dan tidak nyaman. Perawat mengukur suhu tubuh klien dan memberikan selimut (Potter \& Perry, 2005).

3. Perbedaan suhu tubuh sebelum dan setelah pengaturan suhu ruangan $22^{\circ} \mathrm{C}$

Berdasarkan hasil penelitian rata rata perubahan suhu tubuh sebelum diberikan intervensi dengan suhu $16^{\circ} \mathrm{C}$ sebesar $35.46^{\circ} \mathrm{C}$ dan setelah diberikan intervensi pengaturan suhu ruangan $22^{\circ} \mathrm{C}$ terjadi peningkatan suhu tubuh dengan ratarata $36.83^{\circ} \mathrm{C}$ atau rata-rata selisih $1.37^{\circ} \mathrm{C}$ hal ini menunjukan ada perbedaan yang bermakna perubahan suhu tubuh antara sebelum dilakukan intervensi dan setelah dilakukan intervensi pada pasien post operasi.Pengaturan suhu di ruang pemulihan sangat mempengaruhi terhadap perubahan suhu tubuh pasien pasca operasi dikarenakan factor anastesi, cairan dan suhu ruangan operasi yang dingin rata rata $16-20^{\circ} \mathrm{C}$ sehingga membuat pasien mengalami kedinginan. Metode yang dilakukan untuk mengatasi perubahan suhu tubuh pada pasien dengan cara meningkatkan pengaturan suhu ruangan normal $22^{\circ} \mathrm{C}$ sehingga akan meningkatkan Perubahan suhu tubuh pasien post operasi di ruang.

Hal ini di dukung oleh teori Potter \& Perry (2005), yang menyatakan bahwa lingkungan ruang operasi dan ruang pemulihan sangat dingin akan menurunan tingkat fungsi tubuh klien menyebabkan turunnya metabolisme dan menurunkan suhu tubuh. Apabila klien mulai sadar, mereka mungkin akan mengeluh kedinginan dan tidak nyaman.

Perawat mengukur suhu tubuh klien dan memberikan selimut. Pasien yang telah menjalani pemajanan lama terhadap dingin dalam ruang operasi dan menerima banyak infus intravena dipantau terhadap hipotermia,ruangan dipertahankan pada suhu yang nyaman dan selimut disediakan untuk mencegah menggigil (Smeltzer, 2002). 
4. Perbedaan suhu tubuh sebelum dan setelah pada kelompok kontrol

Berdasarkan hasil penelitian rata rata perubahan pengukuran suhu tubuh pretest $16^{\circ} \mathrm{C}$ sebesar $35.12^{\circ} \mathrm{C}$ dan setelah posttest didapatkan hasil rata rata suhu tubuh pasien pasca operasi $35.14^{\circ} \mathrm{C}$ dengan selisi rata rata pre dan post sebesar $-0.02^{\circ} \mathrm{C}$ hal ini menunjukan tidak ada perbedaan perubahan suhu tubuh antara sebelum dan sesudah dilakukan pengukuran suhu tubuh pada pasien post operasi.

Pada kelompok kontrol tidak diberikan intervensi pemberian selimut tebal dan pengaturan suhu ruangan tetapi hanya diberikan selimut tipis dari keluarga sehingga tidak ada perubahan suhu tubuh pada pasien pasca operasi.

Penurunan suhu terjadi pada 1 jam pertama setelah anestesi spinal, hal ini selain disebabkan redistribusi panas dari pusat ke perifer karena vasodilatasi akibat blok simpatis, juga karena kehilangan kemampuan termoregulasi tubuh ditandai dengan terjadi penurunan ambang menggigil dan hilangnya vasokonstriksi termoregulasi di bawah daerah blok, simpatik sehingga terjadi peningkatan kehilangan panas dari vasodilatasinya.

Pada bagian yang tidak diberiakn selimut tebal ini proses perpindahan panas meliputi radiasi, konveksi, konduksi, dan evaporasi akan terjadi. Konduksi merupakan proses perpindahan panas secara langsung antara 2 (dua) materi padat yang berhubungan langsung tanpa ada transfer panas molekul. Panas menjalar dari bagian yang suhunya lebih tinggi ke suhu yang lebih rendah dengan besar kalor yang hilang melalui proses ini akan bergantung pada faktor perbedaan suhu antara kulit dan benda padat yang menempel, serta sifat konduktivitas kulit yang dapat mengakibatkan proses konduksi, terutama apabila suhu benda tersebut berbeda jauh di bawah suhu permukaan kulit. Kain alas tempat tidur dan kain steril penutup pasien yang basah karena darah atau cairan irigasi dapat memperbesar derajat konduksi. Proses pelepasan panas tubuh secara konduksi pada penelitian ini masih tetap terjadi. Konveksi adalah perambatan panas yang terjadi melalui media cair atau gas.Besarnya konveksi bergantung pada luas kontak dan perbedaan suhu media. Proses ini dipengaruhi oleh suhu pada permukaan kulit, suhu udara, luas permukaan kulit, dan kecepatan gerak udara di sekitar kulit, hilangnya panas yang dapat terjadi kira-kira $32 \%$

Hal ini sesuai dengan teori Black(2014) dimana Pemberian selimut merupakan suatu cara yang digunakan untuk mencegah penurunan suhu tubuh (hipotermi). Pasien yang telah menjalani pemajanan lama terhadap dingin dalam ruang operasi dan menerima banyak infus intravena dipantau terhadap hipotermi

5. Perbedaan pemberian selimut tebal jenis kain katun, pengaturan suhu ruangan dan kelompok kontrol terhadap perubahan suhu tubuh

Berdasarkan hasil penelitian yang didapatkan rata-rata perubahan suhu tubuh setelah diberikan selimut tebal kain katun pada kelompok intervensi I terhadap perbedaan suhu sebelum dan sesudah intervensi dimana beda mean -1.280 dengan 
nilai signifikan $p$-value $0.000 \leq \alpha 0.05$ artinya terdapat efektivitas yang signifikan dengan selimut tebal jenis kain katun terhadap perubahan suhu tubuh, pada kelompok intervensi II terhadap perbedaan suhu sebelum dan sesudah intervensi dimana beda mean -1.366 dengan nilai signifikan $p$ Value $0.000 \leq \alpha 0.05$ artinya terdapat efektivitas yang signifikan dengan pengaturan suhu ruangan $22^{\circ} \mathrm{C}$ terhadap suhu tubuh dan pada kelompok kontrol tidak terdapat perbedaan suhu sebelum dan sesudah dimana mean -0.020 dengan nilai tidak signifikan $p$-Value0.082 $\geq \alpha$ 0.05 artinya tidak terdapat efektivitas yang signifikan terhadap perubahan suhu tubuh. Dari hasil penelitian yang dilakukan peneliti menunjukan penggunaan selimut tebal jenis kain katun, pengaturan suhu ruangan terbukti berpengaruh terhadap perubahan suhu tubuh bila dibandingkan dengan kelompok kontrol tanpa diberikan intervensi.

Hal ini di dukung oleh penelitian yang dilakukan oleh Kusuma I Gusti Bagus Intan Wijaya tahun 2009 di Ruang Pemulihan OK RSUD Sanjiwani Gianyar dengan judul Perbedaan Efektifitas Pemberian Selimut Tebal dan Lampu Penghangat Pada Pasien Pasca Bedah Section Caesaria Yang Mengalami Hipotermi.

Metode penelitian, dalam penelitian ini menggunakan jenis penelitian Pre-experimentaldesign dengan rancangan Intact-Group Comparison design, yang memungkinkan mengungkap sebab akibat tanpa menggunakan kelompok kontrol dan membandingkan hasil intervensi yang diberikan. Hasil Penelitian, Dari 16 responden pada kelompok perlakuan selimut tebal nilai rata-rata suhu awal responden sebelum diberikan tindakan adalah $34,0^{\circ} \mathrm{C}$ dan rata-rata waktu kembalinya suhu tubuh kembali normal pada tindakan selimut tebal ini adalah 65,9 menit. Dimana memiliki nilai minimum 50 menit dan nilai maksimum 85 menit. Sedangkan pada 16 responden pemberian lampu penghangat nilai rata-rata suhu tubuh pasien sebelum diberi tindakan adalah $34,060^{\circ} \mathrm{C}$ dan memiliki ratarata waktu kembalinya suhu tubuh ke rentang normal adalah 49,06 menit. Pada kelompok ini memiliki nilai minimum 25 menit dan nilai maksimum 70 menit. Dengan ratarata suhu awal yang cenderung sama yaitu kelompok selimut tebal $34,00^{\circ} \mathrm{C}$ dan kelompok lampu penghangat $34,06^{\circ} \mathrm{C}$ mendapatkan hasil rata-rata waktu masing-masing yaitu pada kelompok selimut tebal dengan ratarata waktu 65,9 menit dan pada kelompok lampu penghangat dengan rata-rata waktu 49,06 menit didapatkan selisih rata-rata waktu pada kedua kelompok adalah 65,9 $49,06=16,84$ menit.

Hal ini sesuai dengan teori Black 2014 dimana Pemberian selimut merupakan suatu cara yang digunakan untuk mencegah penurunan suhu tubuh (hipotermi). Pasien yang telah menjalani pemajanan lama terhadap dingin dalam ruang operasi dan menerima banyak infus intravena dipantau terhadap hipotermi. Proses pemberian selimut dapat meningkatkan suhu tubuh pasien post operasi hal ini dikarenakan bahan selimut bersifat halus, lembut dan tidak panas dapat menghantarkan efek hangat ketubuh pasien melalui proses konduksi dan 
evaporasi. Menurut Tamsuri (2007), mekanisme kehilangan panas melalui kulit yaitu secara konduksi dan evaporasi. Konduksi adalah perpindahan panas akibat paparan langsung kulit dengan benda-benda yang ada disekitar tubuh sedangkan evaporasi (penguapan air dari kulit) dapat memfasilitasi perpindahan panas tubuh. Suhu tubuh dapat mengalami pertukaran dengan lingkungan, artinya panas tubuh dapat hilang atau berkurang akibat lingkungan yang lebih dingin. Begitu juga sebaliknya, lingkungan dapat mempengaruhi suhu tubuh manusia. Perpindahan suhu antara manusia dan lingkungan terjadi sebagian besar melalui kulit. Proses kehilangan panas melalui kulit dimungkinkan karena panas diedarkan melalui pembuluh darah dan juga disuplai langsung ke fleksus arteri kecil melalui anastomosis arteriovenosa yang mengandung banyak otot. Kecepatan aliran dalam fleksus arteriovenosa yang cukup tinggi (kadang mencapai $30 \%$ total curah jantung) akan menyebabkan konduksi panas dari inti tubuh ke kulit menjadi sangat efisien. Dengan demikian kulit merupakan radiator panas yang efektif untuk keseimbangan suhu tubuh.

Lingkungan ruang operasi dan ruang pemulihan sangat dingin. Penurunan tingkat fungsi tubuh klien menyebabkan turunnya metabolisme dan menurunkan suhu tubuh. Apabila klien mulai sadar, mereka mungkin akan mengeluh kedinginan dan tidak nyaman. Perawat mengukur suhu tubuh klien dan memberikan selimut (Potter \& Perry, 2005).

\section{Efektifitas pemberian selimut tebal dan pengaturan suhu ruangan terhadap perubahan suhu tubuh}

Hasil penelitian ini menunjukan bahwa rata rata selisih perubahan suhu tubuh pada kelompok intervensi sebelum dan setelah pemberian selimut tebal kain katun adalah $36.486^{\circ} \mathrm{C}$ dengan standar deviasi $0.324^{\circ} \mathrm{C}$. rata-rata selisi perubahan pada kelompok intervensi sebelum dan setelah pengaturan suhu ruangan $22^{\circ} \mathrm{C}$ adalah $36.833^{\circ} \mathrm{C}$ dengan standar deviasi $0.205^{\circ} \mathrm{C}$

Hasil penelitian ini juga menunjukan bahwa rata rata selisih perubahan suhu tubuh pada dua kelompok dalam kelompok intervensi pemberian selimut tebal kain katun sebesar $1,28^{\circ} \mathrm{C}$ dengan standar deviasi $0.252^{\circ} \mathrm{C}$ pada kelompok intervensi pengaturan suhu ruangan rata rata $1,36^{\circ} \mathrm{C}$ dengan standar deviasi 0.257 analisis hasil uji $t$ berpasangan menunjukan ada perbedaan selisi rata rata perubahan suhu tubuh yang bermakna $\mathrm{p}$-Value $0.002 \leq \alpha 0.05$.

Berdasarakan hasil rata rata perubahan suhu tubuh pada kelompok tersebut, maka kelompok intervensi pengaturan suhu ruangan $22^{\circ} \mathrm{C}$ memiliki nilai yang lebih besar dibandingkan dengan kelompok intervensi pemberian selimut tebal kain katun. Mengacu ke nilai tersebut menunjukan bahwa pengaturan suhu ruangan lebih efektif meningkatkan perubahan suhu tubuh dibandingkan dengan pemberian selimut tebal.

Hasil penelitian yang didapatkan rata-rata Rumah Sakit tipe $B$ di Provinsi gorontalo masih menggunakan suhu ruangan $16^{\circ} \mathrm{C}$ sampai $18^{\circ} \mathrm{C}$ di ruang pemulihan hal inilah yang menyebabkan pasien post 
operasi mengalami kedinginan akibat dari suhu yang tidak disesuaikan dengan sop yang ada.

Hal ini sejalan dengan teori perry dan potter (2005) suhu ruangan pemulihan atau recafri berkisar $22^{\circ} \mathrm{C}$ sampai $26^{\circ} \mathrm{C}$

A. Keterbatasan penelitian

Keterbatasan yang peneliti temukan selama melakukan penelitian adalah :

1. Ruang pemulihan (recovery room) masih satu ruangan dengan pintu masuk pasien.

2. Suhu ruangan yang tidak optimal masih menggunakan Ac Split tanpa menggunakan suhu ruangan

3. Jumlah pengunjung perawat yang terlalu banyak di ruang $R R$ dan ruang $R R$ yang selalu terbuka

B. Implikasi Hasil Penelitian

1. Implikasi Terhadap Pelayanan Keperawatan

Penelitian ini menunjukan suatu bukti pemberian selimut tebal dan pengaturan suhu ruangan yang meningkatkan suhu tubuh pasien pasca operasi

2. Implikasi Terhadap Penelitian Penelitian ini dapat dijadikan dasar bagi peneliti lain yang berhubungan dengan penatalaksanaan pencegahan hipotermi pada pasien pasca operasi

3. Pendidikan Keperawatan

\section{Conclusion}

Penelitian ini memiliki dampak dan wawasan serta pengetahuan yang luas kepeda perawat dalam memberikan asuhan keperawatan.

1. Karakteristik responden pasien post operasi di Ruang Pemulihan
Instalasi Bedah Sentral Ruamh Sakit Tipe B Provinsi Gorontalo sebagian besar responden berusia 36 - 45 tahun (80\%), jumlah responden jenis kelamin sebagian besar perempuan ( $60 \%$ ) dan pendidikan sebagian besar adalah SMA (53.3\%)

2. Terdapat perbedaan suhu tubuh sebelum dan setelah pemberian selimut tebal kain kontrol selama 60 menit

3. Terdapat perbedaan yang bermakna suhu tubuh sebelum dan setelah pengaturan suhu ruangan $20^{\circ} \mathrm{C}$ selama 60 menit

4. Tidak terdapat perbedaan suhu tubuh sebelum dan setelah pada kelompok control selama 60 menit

5. Pengaturan suhu ruangan $22^{\circ} \mathrm{C}$ lebih efektif terhadap perubahan suhu tubuh pasien post operasi dan selimut tebal juga mempengaruhi peningkatan suhu tubuh.

\section{Reference}

Alimul A. A. (2007). Riset keperawatan dan Teknik penulisa IImiah. Jakarta: Salemba Medika.

Arikunto.(2002). Prosedur Penelitian Suatu Pendekatan Praktek. Jakarta: Rineka Cipta.

Muttaqin Arif\& Kumala Sari.(2009). Keperawatan perioperatif. Jakarta: Salemba Medika

Barbara Kozier.(2010).Buku Ajar Fudamental Keperawatan. Jakarta. EGC 
Black Joyce M. (2014). Keperawatan medical bedah. Edisi 8 Buku I. Salemba Medika 271-283 (2014). Keperawatan Medikal Bedah. Edisi 8 Buku 3.Salemba Medika 1067-1082

David Arnot, dkk.(2009). Pustaka Kesehtan Populer Saluran Pencernaan, Volume4. Jakarta: PT Bhuana IImu Populer.

FKUI.(1995). Kumpulan Kuliah IImu Bedah. Binaputra Aksara.

Gilman \&Goodman..(2006). Dasar Farmakologi Terapi.Volume 1. Jakarta: EGC.

Gruendemann, J. Barbara. (2006). Buku Ajar Keperawatan Perioperatif. Vol 1. Jakarta: EGC.

Harun, (2014). Efektivitas Pemberian Selimut Tebal Terhadap Perubahan Suhu Tubuh Pasien Post Operasi Di Ruang Pemulihan RSUD MM Dunda Limboto

Kusuma. (2013). Perbedaan Efektifitas Pemberian Selimut Tebal dan Lampu Penghangat Pada Pasien Pasca Bedah Section Caesaria Yang Mengalami Hipotermi Di Ruang Pemulihan OK RSUD Sanjiwani Gianyar

King, Maurice \& Bewes, Peter.(2001).

Bedah Primer Trauma.Jakarta : EGC.
Martha Raile Allgood. (2014).Pakar Teori Keperawatan.Elsever. Singapura

Nursalam.(2008). Konsep dan Penerapan Metodologi Penelitian IImuKeperawatan. Jakarta: Salemba Medika.

Potter.P A. dan Perry. Anne Griffin. (2005). Fundamental Keperawatan: Konsep,Proses dan Praktik. Alih bahasa: Yasmin Asih, dkk. Edisi 4.Vol 1.Jakarta: EGC.

Pamoentjak.(2009).

Kamus Kedokteran. Djambatan: Jakarta.

\section{Paul G. Barash, MD dkk.(2009). Clinical Anesthesia.Wolters Kluwer Business.}

Sherwood, Lauralee.(2011). Fisiologi Manusia dari Sel Ke Sistem. Jakarta. EGC

.(2016). Fisiologi Manusia dari Sel Ke Sistem. Edisi 8 Jakarta EGC

Sugiyino.(2007). Statistika Untuk Penelitian. Alfabeta: Bandung. (2013). Metode Penelitian Bisnis.Alfabeta : Bandung

Smeltzer, S. C. (2010). Buku Ajar Keperawatan Medikal Bedah Brunner \& Suddarth. Alih bahasa: Agung Waluyo, dkk. Ed. 8. Cetakan I. Jakarta: EGC. 
(2014). Buku Ajar

Keperawatan Medikal

Bedah.Edisi 8.Volume 3.

Jakarta EGC

Sjamsuhidajat, R. (2005). Buku Ajar

IImu Bedah.Edisi Revisi.

Jakarta: EGC.

Sutisna Himawan. (2014). Kumpulan

Kuliah Patologi. FKUI

Said.(2002). Anastesiologi.Edisi

2.Fakultas Kedokteran

Universitas Indonesia.

Tamsuri.(2007). Tanda-Tanda Vital

Suhu Tubuh. Jakarta. EGC

Widyawati, (2013).pengaruh tindakan keperawatan pemberian selimut hangat terhadap kembalinya suhu tubuh normal pada pasien yang mengalami hipotermi setelah menjalani operasi dengan anastesi spinal di RSUD Palembang BARI. 